\title{
Alternative Bus Stop Configuration: An Analysis of the Effects of Bus Bulbs
}

Kay Fitzpatrick, Kevin Hall, Melisa Finley; and Stephen Farnsworth Texas Transportation Institute

\section{$\overline{\text { Abstract }}$}

Bus bulbs are sections of sidewalk that extend from the curb of a parking lane to the edge of the through lane. A major advantage of using bus bulbs is the creation of additional space at a bus stop for shelters, benches, and other bus patron improvements when the inclusion of these amenities would otherwise be limited without the additional space.

Several large cities on the West Coast have begun to explore bus bulbs as one of many strategies used in developing a transit preferential program. Researchers visited four transit agencies that use bus bulbs (San Francisco, Portland, Seattle, and Vancouver, British Columbia) to observe and document existing and planned bus bulbs. Before and after studies were conducted to determine if there was a change in pedestrian and traffic operations after the installation of bus bulbs. The bus bulb design was clearly an improvement in pedestrian space as compared to the bus bay design. The average amount of available space for pedestrians and transit patrons alike improved from 19 to 44 square feet/pedestrian ( 1.8 to $4.1 \mathrm{sq} \mathrm{m} / \mathrm{ped}$ ) after the bulb was constructed. The replacement of a bus bay with a bus bulb improved vehicle and bus speeds on the block. The block with the farside stop saw a statistically significant increase in vehicle travel speed during both nonpeak (9.5 to $15.7 \mathrm{mph}[15.3$ to 25.3 $\mathrm{km} / \mathrm{h}]$ ) and peak (11.4 to $20.9 \mathrm{mph}$ [ 18.4 to $33.6 \mathrm{~km} / \mathrm{h}]$ ) periods. 


\section{Introduction}

Bus bulbs, also known as nubs. curb extensions, or bus bulges, are sections of sidewalk that extend from the curb of a parking lane to the edge of the through lane. They operate similar to curbside bus stops. Buses stop in the traffic lane instead of weaving into a parking-lane curbside stop. A major advantage of using bus bulbs is the creation of additional space at a bus stop for shelters, benches, and other bus patron improvements when the inclusion of these amenities would otherwise be limited without the additional space.

\section{Research Objectives and Scope}

A review of literature and transit agencies as part of a Transit Cooperative Research Program (TCRP) project (Fitzpatrick et al. 1996) revealed that little information is available on bus bulbs. San Francisco planned to convert several bus bays to bus bulbs during the late 1990s. As part of a pavement rehabilitation project during 1999, stops located on Mission Street from Cesar Chavez to Santa Marina were converted. The advanced notice and timing of the construction schedule for the nine stops on Mission Street provided opportunity for a before and after research effort that could examine the effects of converting a bus stop from a bus bay design to bus bulb design. Therefore, TCRP sponsored another study (Fitzpatrick et al. 2000) that included the following objectives:

- collect information on when bus bulbs should be considered and lessons learned from those cities that use the bus bulb configuration, and

- determine the impact of the installation of bus bulbs on transit operations, vehicular traffic, and nearby pedestrian movements at selected sites in San Francisco.

\section{Review of Selected Cities' Practices}

Several large cities on the West Coast have begun to explore bus bulbs as one of many strategies used in developing a transit preferential program. Researchers visited four transit agencies that use bus bulbs (San Francisco. Portland, Seattle, and Vancouver, British Columbia) to observe and document existing and planned bus bulbs. These cities all have high development densities, 
" ell-developed transit corridors, and a high level of transit patronage. Each of these cities also has a strong pedestrian and bicycle program to augment transit operations.

\section{San Francisco}

The concept or use of bus bulbs in San Francisco dates back to the early 1970 s with the adoption of the Transit Preferential Streets (TPS) program in 1973. Under this program, several "Transit-First" strategies were identified, which were designed to create a more "transit-friendly" environment within the City of San Francisco, especially within those corridors where there was already a large use of transit. Bus bulbs were identified, along with several other measures, as a potential tool for implementing the TPS program (Watry et al. 1996). Several older locations of bus bulbs are scattered throughout the city. More recently, nine bus bulbs were added to south Mission Street.

Transit ridership is high throughout the City of San Francisco. Therefore, typical candidate locations are usually identified by level of transit ridership, frequency of service, and presence of existing transit infrastructure. Areas with high auto-bus conflicts are also given priority consideration along with pedestrian congestion on the sidewalk near the bus stop zone.

Typical length of a bus bulb in San Francisco is 140 feet $(42.7 \mathrm{~m})$; standard width is 6 feet $(1.8 \mathrm{~m})$, which is nearly equal to the width of the parking lane. Similar to other cities, maintaining appropriate storm water drainage along the roadway was the most challenging and costly element of the design. The approximate cost to design and construct nine Mission Street bus bulbs was $\$ 500,000$. Figures 1 and 2 are examples of bus bulbs used in San Francisco. The bulbs were constructed as part of an overall street rehabilitation project. The bulbs were not a "stand-alone" project, which can raise unique challenges associated with retrofitting bulbs into existing roadway cross sections and grades.

\section{Portland}

The City of Portland has several existing and pending bus bulb locations. Contrary to other cities, a majority of the bulbs are being installed for reasons other than transit. The pedestrian and bicycle program in Portland is very 


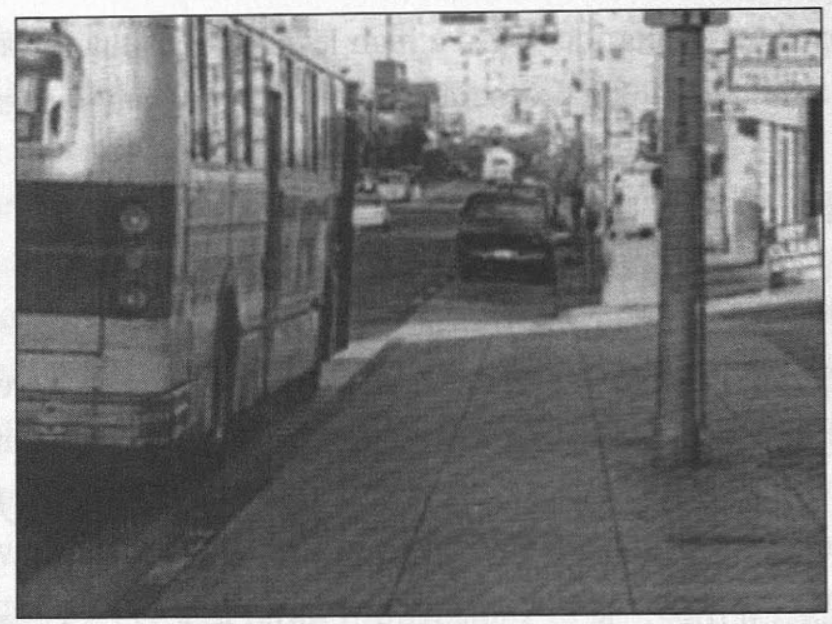

Figure 1. Example of San Francisco bus bulb

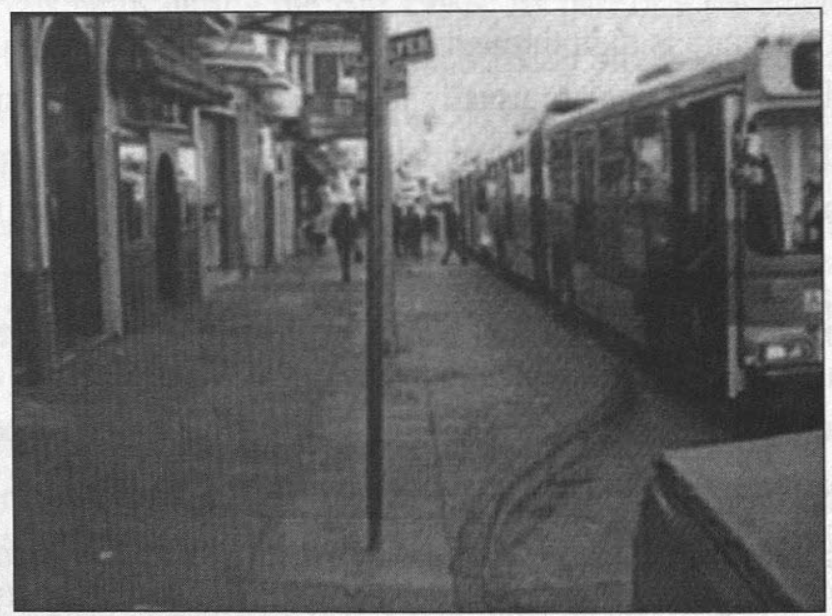

Figure 2. Multiple buses at a San Francisco bulb

strong and influential. Consequently, a majority of the bulbs are being installed as part of traffic-calming measures or to reduce pedestrian crossing times at intersections. To highlight this pedestrian-to-transit policy, the opposing curb is also reconstructed with a pedestrian bulb to shorten the crossing length of the street for pedestrians (Figure 3).

Currently, the standard width of all bulbs in Portland is 6 feet $(1.8 \mathrm{~m})$, which provides a 2 -foot $(0.6 \mathrm{~m})$ "shy" zone between the bulb and traffic. The 


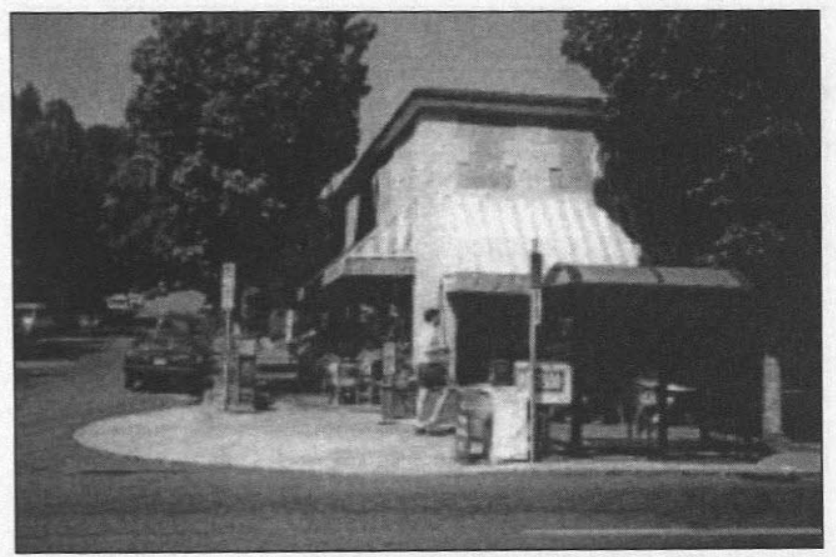

Figure 3. Pedestrian bulb used with bus bulb in Portland

"shy" zone was selected in consideration of bicyclists who use the curbside parking lane as a travel lane. The city will not stripe a bike lane on streets that have lanes less than or equal to 14 feet $(4.3 \mathrm{~m})$ wide. Portland will consider striping a bike lane when the lane width is 15 feet $(4.6 \mathrm{~m})$ or more. Figure 4 illustrates bicycle lane treatments near bus bulbs in Portland.

The length of the bulbs is highly variable throughout the City and appears to be dependant on the width of the street, amount of existing parking, and the policy regarding how many doors are used for boarding and alighting from the transit vehicle. The preferred location of bus stops in the Portland region is the nearside of intersections. Because of the front-end boarding and alighting policy and the retirement of articulated buses, Portland Tri-MET may consider shorter bulbs than other areas of the country. The length of the most recent bus bulbs that were installed on Sandy Street are 30 feet $(9.2 \mathrm{~m})$ (Figure 5). TriMET is debating the installation of 20 -foot $(6.1 \mathrm{~m})$ bulbs in the downtown area where boarding and alighting would occur in the front of the bus only.

Retrofitting or rebuilding the street to install a bulb has raised concerns with requirements in the Americans with Disabilities Act (ADA) concerning wheelchair lift deployment. Maintaining appropriate slope at the bus stop is the primary concern. Where bulbs are short in length, it has been difficult to accommodate the lift as well as locate other pedestrian amenities (e.g., shelter, 


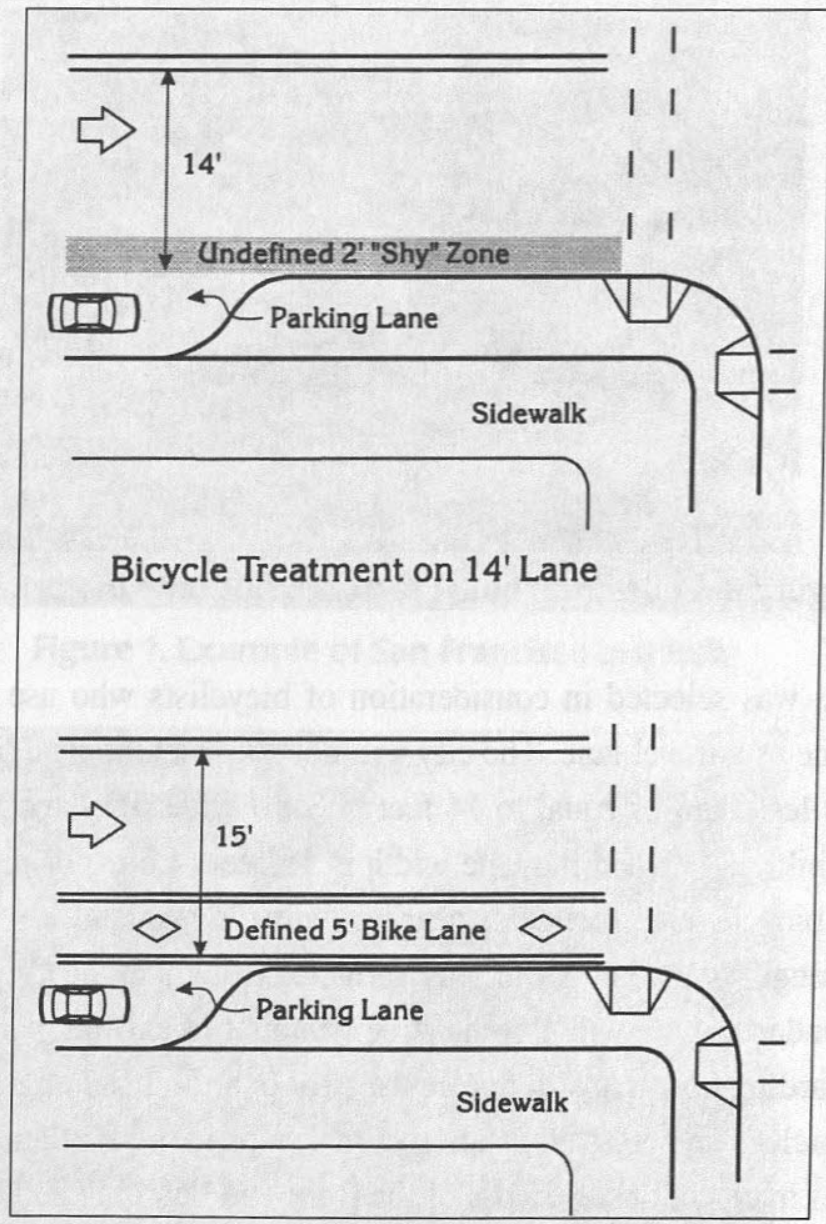

Figure 4. Bike lane treatments with bus bulbs in Portland

bench). Transit vehicle operators have noted difficulties for patrons navigating wheelchairs around "Bus Stop/No Parking" signs and vending machines. The City is considering taping or painting pathways at the stops to illustrate where vending machines cannot be placed. Furthermore, retrofitting a site can raise complex design issues associated with storm water drainage and increase the cost of the project dramatically. The approximate cost for the Portland bulbs has been between $\$ 15,000$ to $\$ 30,000$ per bulb pair with slightly higher costs in some instances due to individual site characteristics. 


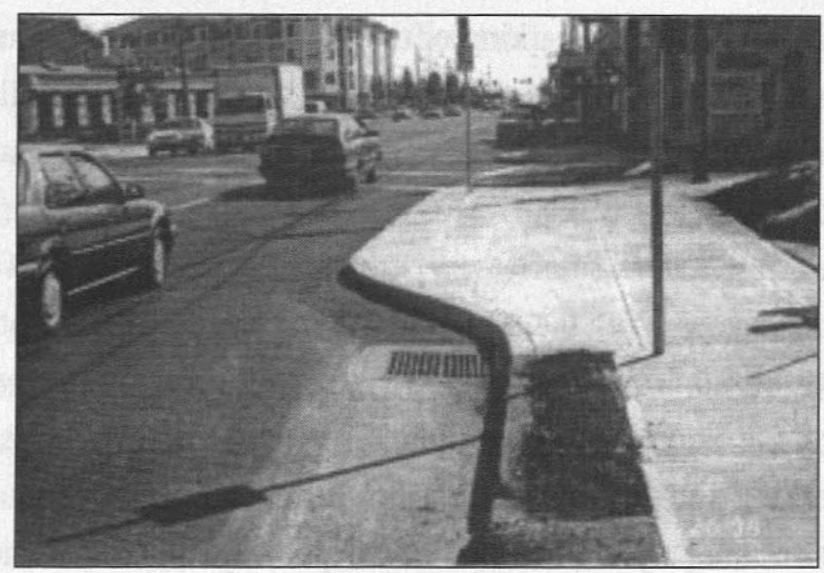

Figure 5. Nearside bus bulb on N. Sandy Street at N.E. $67^{\text {th }}$ (Portland)

\section{Seattle}

The City of Seattle is actively considering the use of bus bulbs. There are three locations of bus bulbs within Seattle proper. Two locations, N.W. Market St. and N.E. Lake City Way, each have a pair of bus bulbs that have been in place for a number of years. Neither location was planned or built as a bus bulb, and both sets were built prior to the advent of any bus bulb design standard. They were originally designed as pedestrian improvements and accordingly vary in size. The third location, University Way, was to serve as a test case for bus bulbs in the region. It was created to demonstrate these improvements (The TRANSPO Group, Inc.; and MAKERS Architecture and Urban Design 1999):

- increase pedestrian-carrying capacity of the sidewalks,

- improve transit travel times in the corridor by consolidating stops and eliminating the bus reentry problem,

- reduce or eliminate adaptive use of store fronts by providing a defined space for waiting bus patrons,

- provide a potential location for bus patron amenities (e.g., bus shelter), and

- demonstrate and/or develop "reasonable criteria" for installing bus bulbs at bus stops. 
Similar to other cities, parking or the availability of parking can be a controversial issue. The length of the bus stop zone prior to installation of the demonstration bulbs was 120 feet $(36.6 \mathrm{~m})$. Length of the bulbs after installation was approximately 80 feet $(24.4 \mathrm{~m})$. The curb return radii of 20 feet/20 feet $(6.1 \mathrm{~m} / 6.1 \mathrm{~m})$ were selected to permit street sweeping and to consume fewer parking spaces. With the 80 -foot $(24.4 \mathrm{~m}$ ) length and 20 foot $/ 20$ foot ( 6.1 $\mathrm{m} / 6.1 \mathrm{~m}$ ) curb return configuration, an additional parking space was added to each side of the street. The consolidation of stops also provided additional room for parking since two curbside stops have been temporarily removed for the demonstration project. The additional parking space and inclusion of a defined waiting area for bus patrons were readily accepted by local businesses.

Complying with design standards as set forth by the ADA guidelines was a very real challenge. In the process of retrofitting the University Way demonstration sites, the City had to grind the street lower to achieve minimum slope standards. Another problem associated with a retrofit design, such as University Way, was drainage. Standing water on the sidewalk could later form as ice and pose a potential danger to pedestrians and waiting passengers. This problem is particularly acute where the bulb joins the sidewalk. Designers are wary of creating joints that would allow water to accumulate rather than drain. Figure 6 is a plan view of one of the demonstration bulbs.

The demonstration project achieved some transit travel time savings in the corridor by increasing the speed of the transit vehicle from 4.5 to $5.7 \mathrm{mph}$ (7.2 to $9.2 \mathrm{~km} / \mathrm{h}$ ) in the corridor (The TRANSPO Group, Inc.; and MAKERS

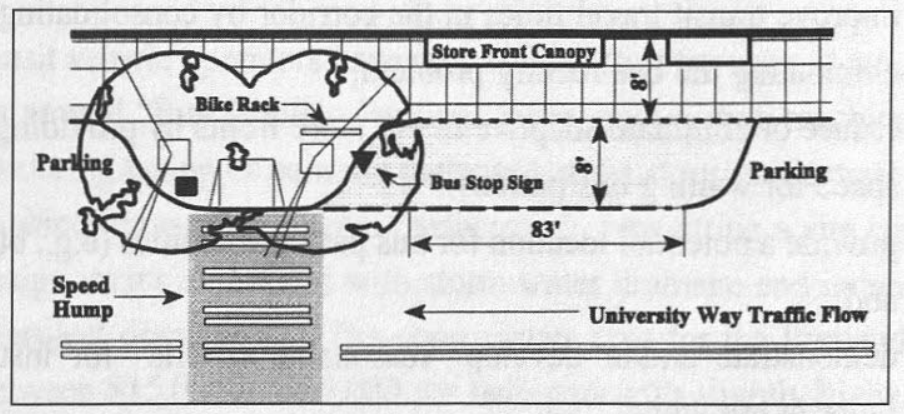

Figure 6. Detail of northbound demonstration bulb in Seattle 
Architecture and Urban Design 1999). Total delay to general-purpose vehicles was minimal. Pedestrian congestion points were also removed from the sidewalk because of the additional space afforded by the bulb. The cost to construct the two demonstration bulbs was $\$ 35,000$. A majority of the expenses was related to drainage and accommodating wheelchair lift deployment.

\section{Vancouver, British Columbia}

The transportation mission statement of Vancouver, British Columbia, is to emphasize transit movement rather than vehicle movement. The City Council, based on a recommendation from an administrative report, has adopted a transit-first policy. Therefore, the City has placed greater emphasis on increased bus service and created a moratorium on additional construction or expansion of freeways. At this time, bus bulbs, or bus bulges, as they are called in Vancouver, have been identified as a potential transit priority measure. It is assumed that bus bulbs will increase bus travel time savings by allowing the bus to stop in the travel lane rather than having to reenter the stream of traffic.

The City of Vancouver is studying the impact of two demonstration bulbs near the University of British Columbia on 10th Avenue at the intersection of Sasamat Street. Currently, no warrants or guidelines have been developed for the installation of bus bulbs, but the design on 10th Avenue may yield standards for design. The width of the demonstration bus bulbs was constrained by the narrowness of 10th Avenue, which is only 52 feet $(15.9 \mathrm{~m})$ wide. The bulb width was restricted to 6.5 feet $(2.0 \mathrm{~m})$ to minimize the potential of having a stopped bus encroach into the second travel lane. Another concern is having enough room for a vehicle to pass the stopped bus without sideswiping the stopped vehicle or encroaching onto the opposing lane.

The length of the bulb is approximately 105 feet $(32.0 \mathrm{~m})$, which accommodates more than one transit vehicle arriving at the stop: articulated ( $60 \mathrm{ft}$ $[18.3 \mathrm{~m}])+$ trolley $(40 \mathrm{ft}[12.2 \mathrm{~m}])$. Figure 7 shows one of the bus bulbs, and Figure 8 presents a detailed plan view of the site with dimensions.

\section{Before and After Studies}

The timing of San Francisco's conversion of several bus bays into bus bulbs provided the opportunity to conduct a direct comparison of the changes 


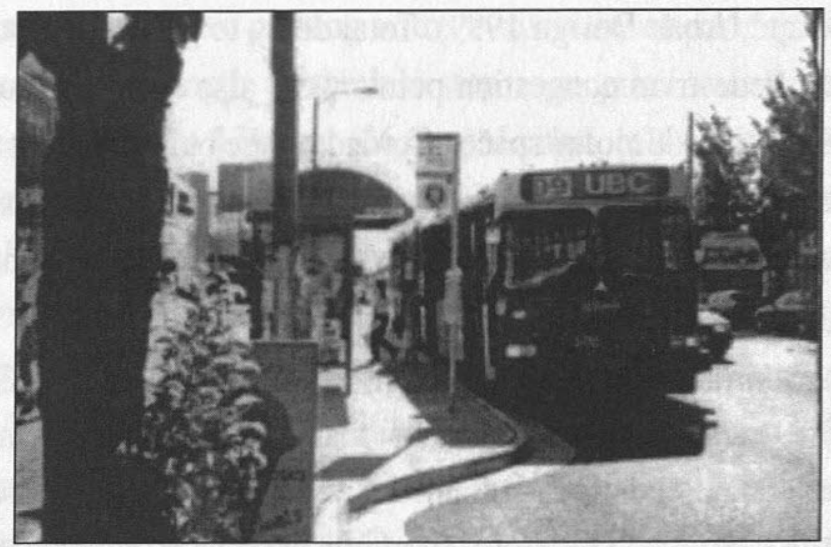

Figure 7. Bus bulge in Vancouver, B.C.

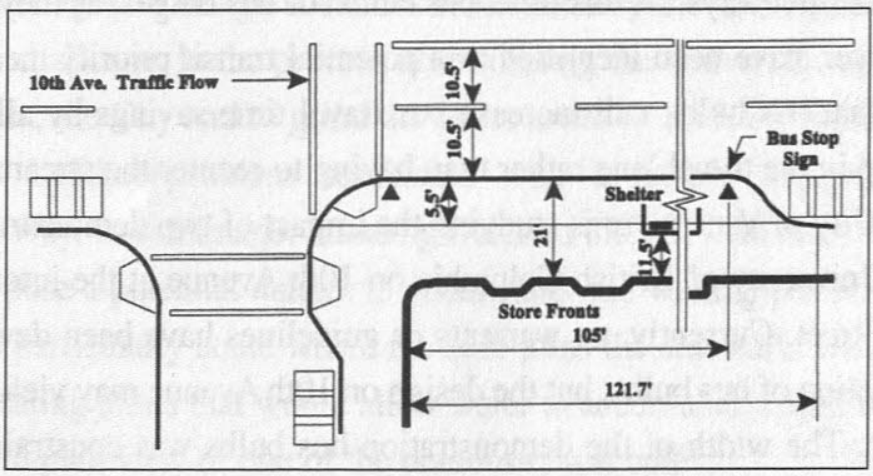

Figure 8. Bus bulge details for site in Vancouver, B.C.

in bus, traffic, and pedestrian operations. The before and after studies were split into two parts: curbside (i.e., pedestrians) and roadway (both buses and general traffic).

\section{Curbside}

The bus bay type of configuration yields limited space to segregate transit activities (e.g., boarding and alighting, waiting patrons) from pedestrian movement on a sidewalk. Bus bulbs are a logical strategy for improving pedestrian congestion in narrow or small areas since bus stops can become unintended bottlenecks or points of congestion on crowded urban sidewalks. By extending the curb toward the outside travel lane, a defined waiting area can 
be provided for bus patrons away from the flow of pedestrian traffic on the sidewalk. Amenities, such as bus shelters, can be stored off of the sidewalk altogether.

Objectives of the curbside before and after studies were to:

- determine if the space available per pedestrian increases with construction of the bus bulb, thereby improving walking speeds, reducing conflict points, and increasing available waiting area for patrons;

- calculate sidewalk level-of-service (LOS) values and determine if it changes with the addition of the bus bulb; and

- determine if the corner operates at a higher level-of-service with the additional room created by the bus bulb.

Only one of nine bus bulbs being constructed was selected for study. Mission Street at 30th Street was chosen because it had the highest pedestrian and boarding and alighting volumes of any of the sites on south Mission Street where the bus bulbs were being constructed. The high pedestrian volumes are created by a Safeway grocery store and Walgreens pharmacy directly adjacent to the bus stop zone, a variety of restaurants and retail establishments in close proximity to the bus stop, and the high volume of children who ride the bus to and from school. Further adding to the pedestrian traffic at the site is the location of two bus stops on 30th Street, which serve as a transfer point from the Mission Street bus routes onto the Divisadero bus route. Data were primarily collected using palmtop computers, video, still photography, and general observations made in the field about pedestrian congregation areas and common travel paths. Figures 9 and 10 show the configuration/layout of the entire intersection prior to and after construction of a bus bulb.

Findings from the before and after curbside studies conducted at Mission and 30th Street in San Francisco include:

- Bus bulb design was clearly an improvement in size as compared to bus bay design. The curb was extended by 6 feet $(1.8 \mathrm{~m})$ over the entire length of the bus stop zone. 


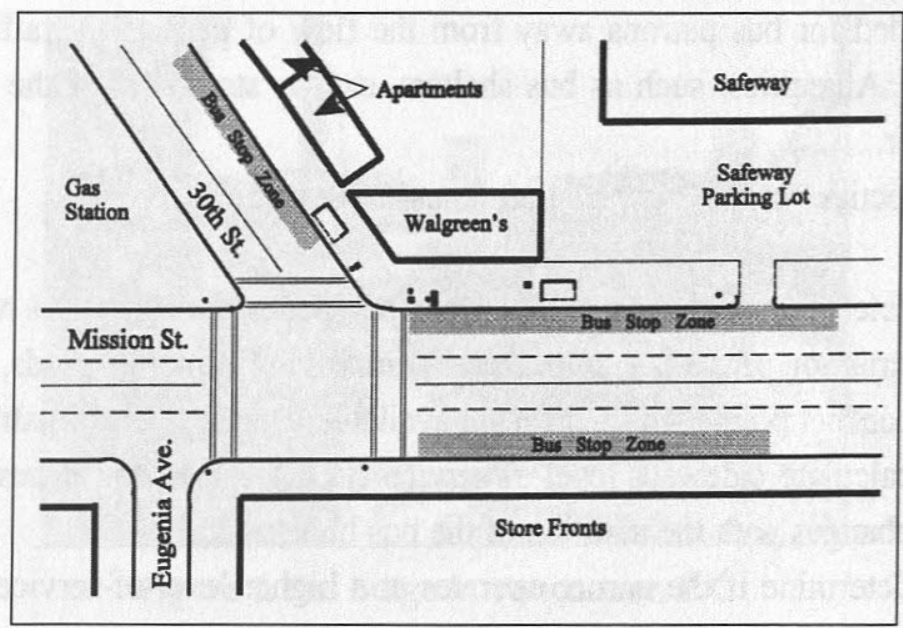

Figure 9. Mission at $30^{\text {th }}$ Street Intersection (bus bay configuration)

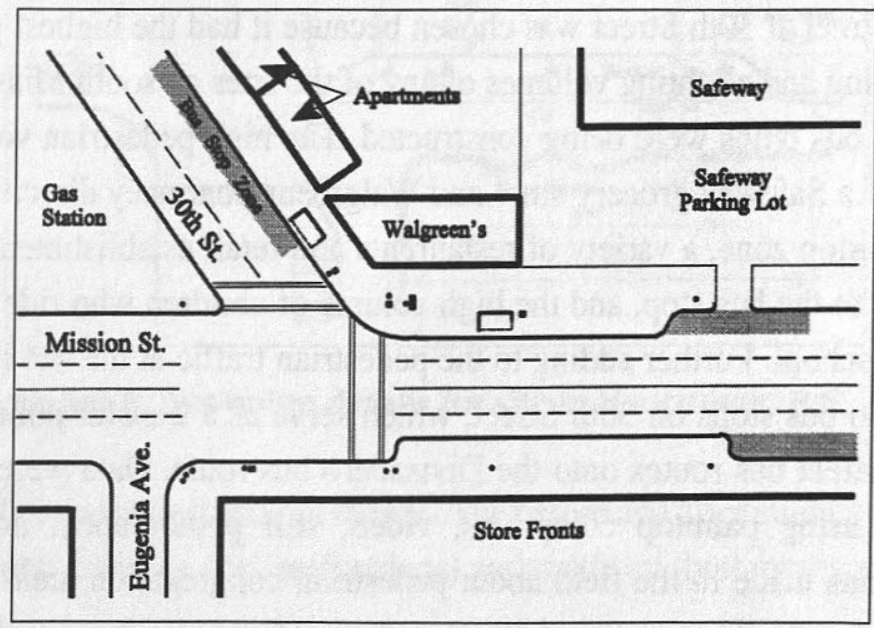

Figure 10. Mission at 30th Street intersection (bus bulb configuration)

- The greatest difference between the two designs was during the boarding and alighting phase of the bus arrival/departure sequence. The average amount of available space for pedestrians and transit patrons alike improved from 19 to 44 square feet/pedestrian (1.8 to $4.1 \mathrm{sq}$ $\mathrm{m} / \mathrm{ped}$ ) after the bulb was constructed. 
- The average flow rate of pedestrians traveling along the sidewalk adjacent to the bus stop improved by approximately 11 percent from 4.0 pedestrian $/ \mathrm{minute} / \mathrm{feet}(13.1 \mathrm{ped} / \mathrm{min} / \mathrm{m})$ at the bay configuration to 3.6 pedestrian/minute/feet $(13.4 \mathrm{ped} / \mathrm{min} / \mathrm{m})$ in the bulb configuration during the four highest 15 -minute increments studied. The data would have shown a greater improvement, but the location of certain street furniture did not change between the two designs.

- Extension of the curb near the crosswalk after the bulb was constructed provided a larger queuing area for pedestrians at the corner. The larger area reduced the number of occurrences of conflicts between those pedestrians waiting to cross the street and those approaching the corner. The curb extension also increased the number of people who complete the crossing of Mission Street and 30th Street within the crosswalk lines. When the bay was present, a number of people were observed "cutting" the crosswalk to reduce their exposure in the street.

\section{Roadway}

Benefits to pedestrians and bus patrons are numerous when a bus bay is replaced with a bus bulb. In addition, buses should operate more efficiently at the bus stop when not required to weave in and out of a bus bay. However, these benefits may be offset by the disadvantage to motorists and other buses. In the bus bulb design, passengers board and alight while the bus is stopped in the travel lane. Being stopped in the travel lane could result in queues forming behind the bus and longer travel times for both vehicles and buses.

Specific objectives of the roadside studies included determining if the following changed from the before period (bus bay) to the after period (bus bulb):

- bus and vehicle speeds near a bus stop (peak and nonpeak time periods),

- bus and vehicle speeds for the corridor (peak time period),

- length of queue behind a bus and driver behavior near the bus stop, and

- bus operations.

Bus speeds represent the speed of buses stopping at a bus stop of interest (as opposed to all buses within the corridor). Vehicle speeds represent the speeds of all vehicles in the traffic stream. Mission Street is a low-speed arterial with 
heavy commercial development (primarily shops and restaurants). The corridor has four lanes without a median and is posted with a $25 \mathrm{mph}(40.3 \mathrm{~km} / \mathrm{h})$ speed limit.

Traffic and bus data were collected at six of the nine bus stops converted as part of the construction project and for the corridor. Data were collected using travel time software, palmtop computers, video, photographs. and general observations made in the field. Figure 11 shows the locations of the researchers and the distances over which the travel times were collected and

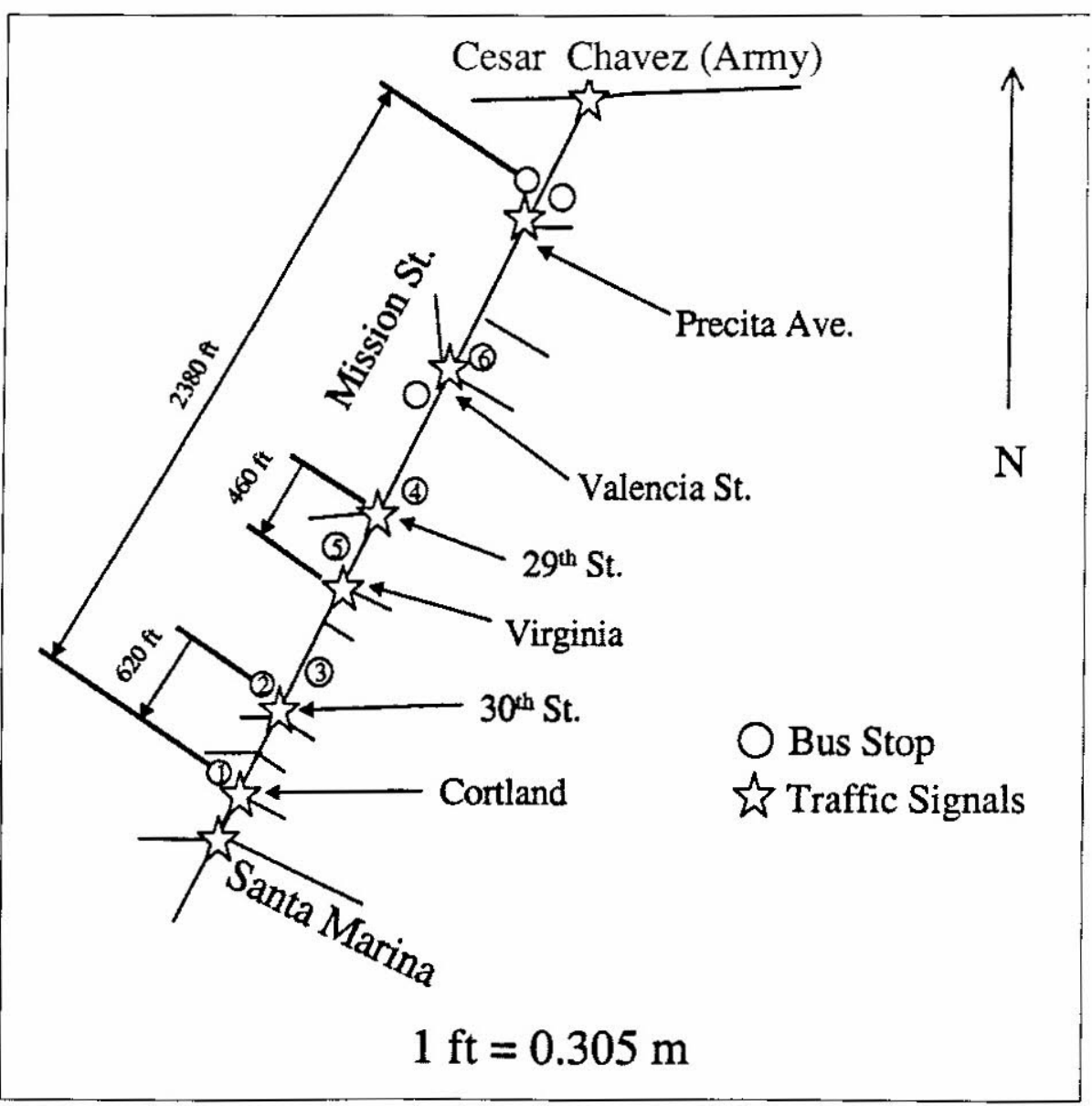

Figure 11. Travel time collection locations 
the six bus stops studied. Sites 1,2, and 5 are nearside stops; sites 3, 4, and 6 are farside stops.

Findings from the before and after roadway studies conducted in San Francisco include:

- Replacement of a bus bay with a bus bulb improved vehicle and bus speeds on the block. The block with the farside stop saw a statistically significant increase in vehicle travel speed during both nonpeak ( 9.5 to $15.7 \mathrm{mph}$ [ 15.3 to $25.3 \mathrm{~km} / \mathrm{h}$ ]) and peak (11.4 to $20.9 \mathrm{mph}$ [18.4 to 33.6 $\mathrm{km} / \mathrm{h}]$ ) periods.

- Average speed for vehicles and buses on the corridor increased with installation of bus bulbs. Buses experienced approximately a 7 percent increase (about $0.5 \mathrm{mph}[0.8 \mathrm{~km} / \mathrm{h}]$ ) for both northbound and southbound directions. Vehicles speeds changed from approximately $15 \mathrm{mph}$ $(24.2 \mathrm{~km} / \mathrm{h})$ to $17 \mathrm{mph}(27.4 \mathrm{~km} / \mathrm{h})(17 \%$ increase $)$ or $22 \mathrm{mph}(35.4$ $\mathrm{km} / \mathrm{h})(46 \%$ increase) for the northbound and southbound directions, respectively. The finding for the vehicles moving in the southbound direction was statistically significant.

- Reduction in travel speeds are assumed to be the consequence of installing bus bulbs because buses are stopping in the travel lane rather than moving into a bus bay; however, on this study travel speeds increased. In the before period when the bus bay configuration was present, the majority of the buses would stop partially or fully in the travel lane rather than pulling into the bay. In addition, buses pulling away from the bay would sometimes use both travel lanes to complete the maneuver. The number of buses affecting vehicles in the outside travel lane may not have greatly changed after the bulb's installation. The number of buses affecting vehicles in both travel lanes did decrease because bus drivers no longer needed to use both travel lanes to leave the bus bulb stop.

- Queues did occur more frequently with the bus bulb design; however, they were generally short, on average, only one to two vehicles long. 
- During the peak period, the number of lane changes was similar for both designs at the farside stop. The nearside stop had a greater number of lane changes with the bulb design than the bay design.

- The average delay to buses attempting to reenter the travel stream was constant from the before to after period at the farside stop. The nearside stop, which experienced higher delays to buses, saw a reduction in the average delay with installation of the bus bulbs.

\section{Conclusions}

Bus bulbs are used in San Francisco, Portland, Seattle, and Vancouver. Compared to other North American cities, these areas have high development density, well-developed transit corridors, urban form of the community, and a high level of transit patronage. The impetuses for installing bus bulbs on a siteby-site basis were similar among the cities that already have bus bulbs. Issues such as transit ridership, traffic volumes, high pedestrian traffic along the sidewalk, and roadway operating speeds guided the inclusion of a bus bulb at a particular site.

Table 1 lists considerations that might be reviewed prior to installing a bus bulb. The comments are in no particular order of importance but reflect the experiences of transit agencies that have installed this type of treatment.

\section{Table 1}

\section{Considerations for Locating Bus Bulbs}

\section{Where to Locate Bus Bulbs}

- High bus patronage

- High pedestrian activity on sidewalk

- Bus reentry problems

- Reduce pedestrian exposure at the crosswalk

- Areas where bus stop consolidation considered desirable

- Communities where transit is given a high priority

- Traffic calming is being considered

- Enhance pedestrian-oriented development

- Additional pedestrian amenities needed
Where Not to Locate Bus Bulbs

- High-speed facilities (generally greater than $45 \mathrm{mph}$ )

- Low transit ridership

- Where on-street parking is not available

- Concerns with queues forming behind stopped buses

- Two-lane streets

- Narrow streets (sideswipe potential)

- Layover locations

- Signalized intersections with capacity concerns

- High vehicular volumes 
Most of the cities visited noted that bus bulbs are a fairly new design consideration in and around bus stops. Therefore, many of the initial installation sites were fact-finding studies as much as they were attempts to improve transit and pedestrian operations around the bus stops. Consequently, designs were highly variable between and within cities. Major site-design findings and issues from the cities include:

- Bus bulbs were always located on streets with 24-hour curbside parking.

- The bus bulb width was essentially determined by the parking lane width. Bulbs are usually 6 feet $(1.8 \mathrm{~m})$ wide with a 1 -foot $(0.3 \mathrm{~m})$ "clear zone" for bicyclists.

- The bus bulb length was highly variable among the cities. Factors highlighted included:

- total number of buses that could potentially arrive at the bus stop at the same time,

- fleets' use of articulated buses,

- fare collection policy (e.g., are all doors used to board and alight or is this controlled?). and

- the bus stop is located at the farside or nearside of the intersection (e.g., a short farside bus bulb may cause the rear of the bus to remain in the intersection).

- Return radii for the curb were frequently determined with the turning radius of street-cleaning machines in mind. However, this was not an issue in Vancouver.

- The speed of the facility was typically below $35 \mathrm{mph}(56.4 \mathrm{~km} / \mathrm{h})$.

- No-parking signs were typically attached to the same pole as the bus stop sign, and the back face of the curb was painted to discourage illegal parking at the bus bulb. Most cities indicated that bus bulbs are a self-enforcing design.

- Drainage is a major issue when considering implementing a bus bulb. Retrofitting a stop with a bulb can create design challenges for drainage, grading, and ADA requirements. This can significantly increase the cost of the project. 
- Bus bulbs can potentially provide the opportunity to consolidate bus stops and, therefore, increase the amount of curbside parking available on a street.

- Location of bus shelters was carefully coordinated to avoid blocking local business signs.

Before and after studies were conducted to determine if there was an improvement in pedestrian operations in and around the bus stop at Mission Street and 30th Street after the implementation of a bus bulb at the site and to determine advantages/disadvantages to traffic and bus operations in urban areas. The bus bulb design was clearly an improvement in size as compared to the bus bay design. The average amount of available space for pedestrians and transit patrons alike improved from 19 to 44 square feet/pedestrian (1.8 to 4.1 $\mathrm{sq} \mathrm{m} / \mathrm{ped}$ ) after the bulb was constructed. Replacement of a bus bay with a bus bulb improved vehicle and bus speeds on the block. The block with the farside stop saw a statistically significant increase in vehicle travel speed during both nonpeak ( 9.5 to $15.7 \mathrm{mph}$ [15.3 to $25.3 \mathrm{~km} / \mathrm{h}$ ) and peak (11.4 to $20.9 \mathrm{mph}$ [18.4 to $33.6 \mathrm{~km} / \mathrm{h}])$ periods.

\section{References}

Fitzpatrick, K., K. Hall, D. Perkinson, L. Nowlin, and R. Koppa. November 1996. Guidelines for the location and design of bus stops. TCRP Report 19.

Fitzpatrick, K., K. Hall, S. Farnsworth, M. D. Finley. August 2000. Evaluation of bus bulbs. TCRP Report 65 .

The TRANSPO Group, Inc., and MAKERS Architecture and Urban Design. 1999. Transportation impact assessment for the University Way bus bulb demonstration project. King County Metro Transit Division.

Highway Capacity Manual. Special Report 209, Third Edition. Transportation Research Board. 1994.

Watry, D., and J. Mirabdal. 1996. Transit preferential streets program in San Francisco. In Compendium of Technical Papers: Institute of Transportation Engineers 66th Annual Meeting. Institute of Transportation Engineers. pp. 314-318. 


\section{About the Authors}

KAY FitZPATRICK (k-fitzpatrick@tamu.edu) is a research engineer with the Texas Transportation Institute in College Station, Texas. She holds a bachelor and master degrees in civil engineering from Texas A\&M University and a Ph.D. from Penn State University. She is a registered professional engineer. Her areas of research interest include traffic operations, roadway design, and safety.

Keviv HALL (kevin-hall@tamu.edu) is an associate research scientist with the Texas Transportation Institute. He holds an undergraduate degree in landscape architecture from Virginia Polytechnic Institute and State University and a master of urban and regional planning from Texas A\&M University. He works in the travel forecasting program in Austin, Texas.

MelisA D. FunLey (m-finley@tamu.edu) is an associate transportation researcher at the Texas Transportation Institute. She received her B.S. and M.S. in civil engineering from Texas A\&M University. Her main research interests are traffic control devices and work zones.

STEPHEx P. FARNwORTH (s-farnsworth44@tamu.edu) is an assistant research scientist at the Texas Transportation Institute in College Station, Texas. He holds a B.E.D. in environmental design and a M.U.P. in urban planning from Texas A\&M University. Mr. Farnsworth has experience in transit planning and research, land-use planning, and travel-demand modeling. 
